\title{
Mean platelet volume in acute myocardial infarction: a case-controlled study
}

\author{
Bimal K. Agrawal', Bharatveer Manchanda' , Akash Garg ${ }^{1}$, Abhishek Mittal', N C. Mahajan² and Usha Agrawal ${ }^{3 *}$
}

*Correspondence: uburra@gmail.com

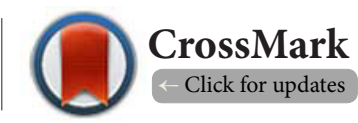

'Department of Medicine, M M Institute of Medical Sciences \& Research, Mullana, India. ${ }^{2}$ Department of Pathology, M M Institute of Medical Sciences \& Research, Mullana, India. ${ }^{3}$ National institute of Pathology, ICMR, New Delhi, India.

\begin{abstract}
Acute myocardial infarction (AMI) is a common emergency which requires timely intervention. Traditionally, its diagnosis is based on symptoms, electrocardiogram and cardiac biomarkers. Symptoms may be nonspecific. Electrocardiogram is easily available, but its sensitivity is low. Cardiac biomarkers are time-dependent and within the normal limit at the first three hours after the initiation of AMI. Mean platelet volume (MPV) has been reported to be high in AMI. Fifty cases of AMI, without prior history of stroke or infarction, were enrolled in the study. Equal number of healthy controls was taken for comparison. Blood sample collected for estimation of MPV was processed within thirty minutes of venesection. MPV was noted to be significantly higher in patients with AMI. Patients with hypertension had significantly higher MPV than hypertensive controls. In subgroup analyses of affected patients, patients with diabetes had significantly higher MPV than those without diabetes. In conclusion, MPV may be a useful adjuvant to the diagnosis of AMI.
\end{abstract}

Keywords: Mean platelet volume, acute myocardial infarction, diabetes mellitus, case control study

\section{Introduction}

The burden of cardiovascular diseases (CVD) is high in South Asian countries [1-3]. Among the CVD, hard coronary heart disease events including acute myocardial infarction (AMI) and coronary death tend to strike at an earlier age in comparison to that in the Western countries. All the common CVD risk factors are more prevalent in developing countries. There are many modifiable and nonmodifiable risk factors for AMI like age, sex, smoking, hypertension, diabetes mellitus etc. However, alcohol consumption does not act as a protective factor for AMI in South Asian natives in previous studies [4]. Diagnosis of myocardial infarction is based on signs and symptoms supported with electrocardiography and cardiac biomarkers like troponin and CPK-MB. Wherever available, coronary angiography and primary percutaneous coronary intervention (PCI) is the main stay of management.

Electrocardiogram (ECG) is an important tool to diagnose myocardial ischemia but the sensitivity of 12 lead ECG in diagnosing AMI was found to be very low $[\mathbf{5 , 6}$. The American College of Cardiology guidelines recommend taking serial ECGs at 5-10 minute interval or continuous monitoring if initial ECG is not diagnostic [7]. Sometimes, even serial ECGs need the help of an expert in ECG interpretation-in cases of left bundle branch block (LBBB) or when features are suggestive of early repolarization. Myocardial infarction can occur in young adults and may be without a known risk factor.

Pathophysiological involvement of platelets in the atherosclerotic process has already been established. Aspirin, an antiplatelet agent is essential in most of the situations whether it is thrombolytic approach or PCI or pharmacoinvasive (thrombolysis followed by PCI) approach. It is well known that platelet rich thrombus is central to the pathology of MI and acute coronary syndrome. Platelet activation and aggregation ignite the process of coagulation and inflammation. It has been observed that larger platelets are more reactive [8]. High mean platelet volume (MPV) has been shown to be associated with AMI [8], acute ischemic stroke [9], preeclampsia [10], acute mesenteric ischemia [11]. We propose that MPV may be an important adjunct in the management of AMI. However, studies have shown conflicting results $[\mathbf{1 2 , 1 3}]$. The present study 
Agrawal et al. Cardiovascular System 2015,

http://www.hoajonline.com/journals/pdf/2052-4358-3-6.pdf

doi: $10.7243 / 2052-4358-3-6$

was undertaken to evaluate the MPV in patients with AMI in comparison to healthy controls.

\section{Materials and methods}

The study was initiated after obtaining Institutional Ethics Committee (IEC) approval of the protocol. The patients admitted in the Emergency department or Intensive Coronary care Unit with the diagnosis of AMI were included for study. The diagnosis of AMI was as per criteria laid down in consensus document of the Joint European Society of Cardiology/American College of Cardiology Committee for the redefinition of myocardial in farction (Table 1) [14]. Fifty consecutive cases of MI and equal number of age ( \pm 5 years) and sex matched controls from the same population who did not have a past history of stroke or MI were enrolled for this study. Informed written consent was obtained from each participant. The exclusion criteria included inflammatory diseases (like rheumatoid arthritis, systemic lupus erythematosus, inflammatory bowel disease etc.) severe liver disease, renal disease, myeloproliferative disorder, thrombotic thrombocytopenic purpura (TTP) and idiopathic thrombocytopenic purpura. Only newly diagnosed cases were included in the study. Patients suspected to have AMI were assessed and investigated immediately on arrival to the ER. Samples for MPV estimation and other blood investigations were collected. Blood samples were collected in ethylene diamine tetraacetate (EDTA) vacutainer for MPV and processed within 30 minutes of venesection. Platelet size tends to increase at room temperature on storage in first two hours and subsequently remain relatively stable for upto eight hours [15]. Dastjerdi et al., assured that MPV measurement can be accurate if sample is analysed within one hour of collection [16]. The resident physician involved in the study was assigned to adhere to the time frame to minimize in vitro increase in platelet volume. All patients were managed according to the standard treatment guidelines under the physician in charge of the case. MPV was analyzed in Melet Schloesing MS9-5 hematology analyser. The mean difference in the subgroups was compared using Students T-test. Receiver operating characteristic (ROC) curve analysis was performed on the MPV values to find a cut-off with maximum sensitivity and specificity. The statistical analysis was performed using the software SPSS v 16.0.

\section{Results}

The study cohort consisted of 50 patients diagnosed with MI and 50 healthy volunteer controls. The mean age of controls was $54.0 \pm 13.3$ and that in cases was $55.0 \pm 13.6$. There were 38 males in either group. The clinical features are given in Table $\mathbf{2}$. Among the patients, 17 were hypertensive, 28 were smokers and 10 had diabetes mellitus. In the control group, 9 were hypertensive, 26 were smokers and 8 had diabetes mellitus. Forty one of the patients had ST-segment elevation MI (STEMI) and nine had Non-STEMI. The mean MPV in case group was $11.0 \pm 2.2 \mathrm{fl}$ and in control group $7.8 \pm 1.3 \mathrm{fl}(\mathrm{p}=0.000)$. The mean MPV in patients with STEMI was $11.1 \pm 2.2 \mathrm{fl}$ and in those with Non-STEMI was $11.0 \pm 2.3 \mathrm{fl}$ which showed no significant difference between groups.

Comparison between patients and controls of each subgroup showed consistent results that patients had significantly elevated MPV. ROC (receiver operating characteristic) analysis of the MPV values revealed the area under the curve (AUC) to be $88.7 \%$ (95\% CI 82.5-94.9\%) with a $\mathrm{p}=0.000$. Diagnostic test evaluation with a cut-off of 9.15 MPV gives a sensitivity of $76 \%$, specificity of $90 \%$ with a positive predictive value of $88.37 \%$.

In subgroup analysis within the patients, it was found that MPV in those with diabetes was significantly greater than that in patients without diabetes ( $\mathrm{p}=0.023$ ) (Table 2). The correlation was not observed in control subjects with and without diabetes $(\mathrm{p}=0.664)$. Subgroup analysis of smokers vs nonsmokers and hypertensives vs nonhypertensive also did not reach statistical significance in neither cases nor controls (Figure 1).

\section{Discussion}

MPV is a platelet marker which can be obtained as a part of complete blood count(CBC) using an automated hematology counter which measures the average size of platelets present in the blood. In this study MPV was significantly higher in patients with AMI in comparison to the control subjects. There was no significant difference in MPV values between ST elevation and nonST elevation myocardial infarction. This finding was in accordance with the observation by Yekelar et al [17]. AMI occurs due to coronary atherosclerosis and thrombus formation. Platelets play a significant role in atherosclerosis as well as thrombosis $[\mathbf{1 8}, \mathbf{1 9}]$. When atherosclerotic plaque ruptures

Table1. Criteria to diagnose acute myocardial infarction [14].

\begin{tabular}{|c|c|c|c|}
\hline Feature & History $^{\star}$ & ECG criteria & $\begin{array}{l}\text { Cardiac biomarkers } \\
\text { Troponin/CK-MB }\end{array}$ \\
\hline $\begin{array}{l}\text { ST elevation myocardial } \\
\text { infarction (STEMI) }\end{array}$ & Ischemic symptoms & $\begin{array}{l}\text { ST elevation in } 2 \text { or more contiguous leads }\left(^{* *}\right), 0.2 \mathrm{mv} \text { or } \\
\text { more in V1-V3 leads and } 0.1 \mathrm{mv} \text { or more in other leads, } \\
\text { development of pathological q wave }\end{array}$ & Elevated \\
\hline $\begin{array}{l}\text { Non ST elevation } \\
\text { myocardial infarction } \\
\text { (NSTEMI) }\end{array}$ & Ischemic symptoms & $\begin{array}{l}\text { ST depression and or T wave inversion in } 2 \text { or more } \\
\text { contiguous leads }\end{array}$ & Elevated \\
\hline
\end{tabular}


Table 2. Mean platelet volume in the patients in association with risk factors.

\begin{tabular}{|c|c|c|c|c|c|c|}
\hline \multirow[t]{2}{*}{ Characteristic } & \multirow[t]{2}{*}{ Feature } & \multicolumn{2}{|c|}{ Controls } & \multicolumn{2}{|r|}{ Cases } & \multirow[t]{2}{*}{ P-value } \\
\hline & & $\mathbf{n}$ & $\begin{array}{l}\text { MPV in } \mathrm{fl} \\
(\text { Mean } \pm \mathrm{SD})\end{array}$ & $\mathbf{n}$ & $\begin{array}{l}\text { MPV in } \mathrm{fl} \\
(\text { Mean } \pm \text { SD })\end{array}$ & \\
\hline Total cohort & - & 50 & $7.81 \pm 1.28$ & 50 & $11.04 \mathrm{fl} \pm 2.2$ & 0.000 \\
\hline \multirow[t]{2}{*}{ Sex } & Male & 38 & $7.68 \pm 1.28$ & 38 & $11.29 \pm 2.30$ & 0.000 \\
\hline & Female & 12 & $8.15 \pm 1.31$ & 12 & $10.52 \pm 1.94$ & 0.001 \\
\hline \multirow[t]{2}{*}{ Hypertension } & No & 41 & $7.90 \pm 1.22$ & 33 & $9.70 \pm 2.24$ & 0.000 \\
\hline & Yes & 9 & $7.10 \pm 1.28$ & 17 & $11.70 \pm 1.99$ & 0.000 \\
\hline \multirow[t]{2}{*}{ Smoker } & No & 24 & $7.97 \pm 1.38$ & 22 & $10.70 \pm 2.19$ & 0.000 \\
\hline & Yes & 26 & $7.65 \pm 1.21$ & 28 & $11.41 \pm 2.16$ & 0.000 \\
\hline \multirow[t]{2}{*}{ Diabetes Mellitus } & No & 42 & $7.80 \pm 1.80$ & 40 & $10.7 \pm 2.20$ & 0.000 \\
\hline & Yes & 8 & $7.70 \pm 1.68$ & 10 & $12.5 \pm 1.47$ & 0.000 \\
\hline \multirow[t]{2}{*}{ MI } & STEMI & -- & -- & 41 & $11.12 \pm 2.18$ & -- \\
\hline & Non-STEMI & -- & -- & 9 & $11.01 \pm 2.28$ & -- \\
\hline
\end{tabular}
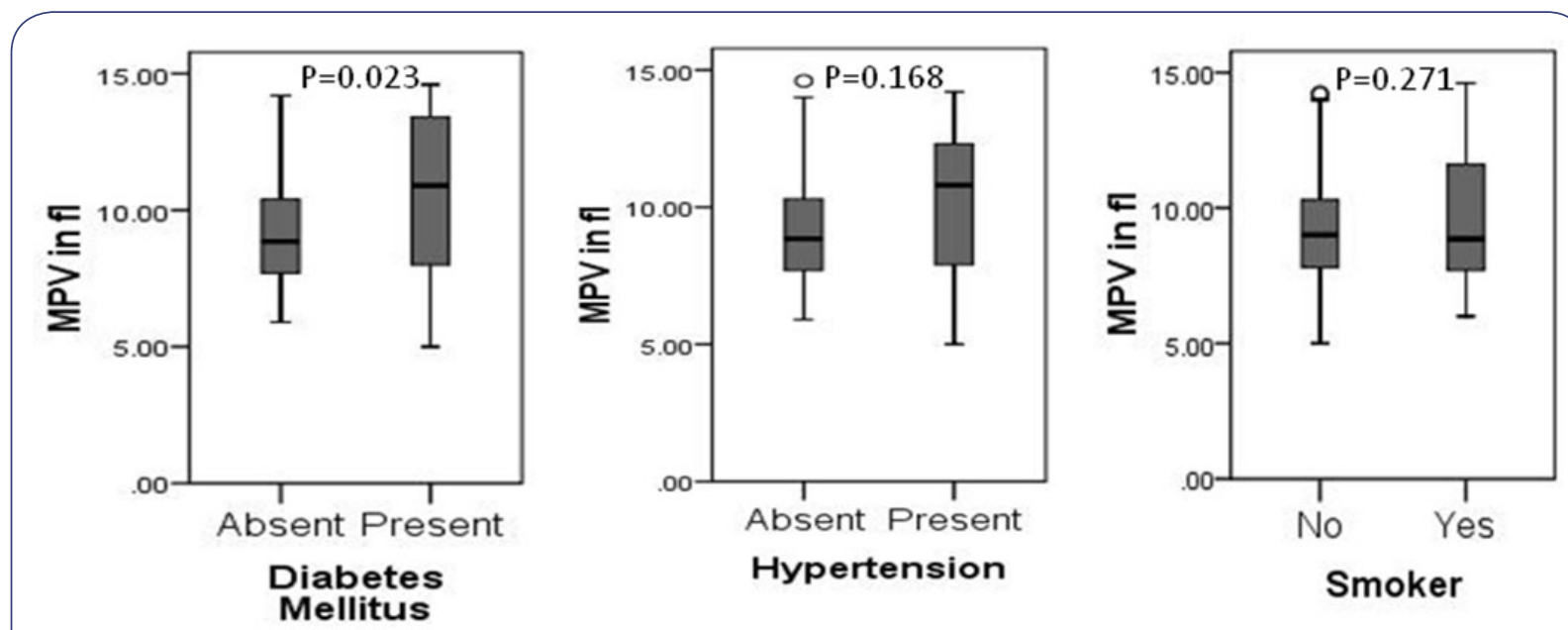

Figure 1. Box-plots depicting the MPV in different groups of patients who have Diabetes mellitus, Hypertension or are smokers. The patients having diabetes are found to have a significantly higher MPV ( $\mathrm{p}=0.023)$.

or erodes platelets are recruited to the exposed subendothelial region and partially occluded vessel becomes completely occluded with the newly formed thrombus. Larger platelets have greater prothrombotic potential and are biologically more potent. Increased platelet volume have been shown to be more reactive with greater production of thromboxane A2, and serotonin. There are other mechanisms by which platelets contribute to development of myocardial infarction via platelet mediated vasoconstriction and inflammation. Chu et al., opined high MPV as a cardiovascular risk factor in a meta-analysis [8].

There are various studies where higher MPV has been correlated with metabolic syndrome, hypertension, increasing age, and hyperlipidemia [20-23] but contradictory studies also exist [24]. In the present study risk factors like smoking and hypertension did not show correlation with MPV in either cases or controls.

Platelets have been implicated in the micro and macrovascular complications of diabetes mellitus [25]. Hendra et al., in their study found that MPV was higher in patients with diabetes and
AMI when compared to those with diabetes but without AMI [26]. Similarly Tuzcu et al., had reported MPV to be higher in patients with diabetes complicated with retinopathy than those without retinopathy [27]. Subgroup analysis of patients with AMI in present study revealed that MPV was significantly higher in patients with diabetes than those without diabetes. Diabetes, due to Insulin deficiency and/or insulin resistance, is considered a prothrombotic state. There are various ways by which diabetes can increase platelet activity [28]. Prolonged hyperglycemia leads to nonenzymatic glycation of platelet suface proteins. Moreover glycoprotein IIb/IIIa is reported to be overexpressed in diabetic individuals [29].

Martin et al., had meticulously evaluated volume and density of platelets in myocardial infarction and suggested that platelet changes were secondary to megakaryocyte abnormalities and these changes preceded myocardial infarction [30]. They also seemed to have increased expression of procoagulant surface adhesion molecules like P-selectin and GPIIb/IIIa. In fact Huczek 
Agrawal et al. Cardiovascular System 2015,

http://www.hoajonline.com/journals/pdf/2052-4358-3-6.pdf

doi: $10.7243 / 2052-4358-3-6$

et al., observed that abciximab (GPIIb/IIIa antagonist) reduced mortality significantly only in patients of myocardial infarction who had high MPV [31]). They further observed that high MPV also carried worse prognosis in terms of poor angiographic reperfusion and higher six months mortality following primary percutaneous coronary intervention (PCI). Martin et al., also found that greater MPV correlated with subsequent mortality and nonfatal myocardial reinfarction [32]. Pereg et al., revealed that thrombolysis (in STEMI) failure rate was significantly higher in patients with high MPV [33]. Slavka et al., in their study concluded that increased MPV may carry increased risk of mortality due to ischemic heart disease which was as much as that due to smoking or obesity [34].

\section{Conclusion}

MPV is a very low cost investigation and can be obtained easily in most health care settings. This study corroborates others observations that MPV is higher in patients with AMI. It is not yet clear whether increase in MPV is the cause or effect of coronary artery occlusion. However we propose that it may be useful as a marker of myocardial infarction in an appropriate clinical situation. Further study may be tested in a larger cohort of patients with AMI to confirm its use as an adjunct to diagnosis.

\section{Competing interests}

The authors declare that they have no competing interests.

\section{Authors' contributions}

Usha Agrawal, Bimal K Agrawal, N C Mahajan-Study plan and protocol designing, manuscript writing. Bimal K Agrawal, BharatveerManchanda, Akash Garg, Abhishek Mittal- Informed consent, acquisition of data Usha Agrawal- Statistical analysis.

\section{Acknowledgement}

We are thankful to all the technical staff of central laboratory of M M Institute of Medical Sciences and Research, Mullana. We also express our gratitude to all the patients and control participants of the study for their whole hearted cooperation.

\section{Publication history}

Editors: Shih Ann Chen, National Yang Ming University, Taiwan. Gen Min Lin, Armed Forces General Hospital, Taiwan. Received: 03 August 2015 Revised: 09 September 2015 Accepted: 22 September 2015 Published: 24 September 2015

\section{References}

1. Reddy KS. Cardiovascular disease in non-Western countries. N Eng/ J Med. 2004; 350:2438-40. | Article | PubMed

2. Yusuf S, Reddy S, Ounpuu S and Anand S. Global burden of cardiovascular diseases: part I: general considerations, the epidemiologic transition, risk factors, and impact of urbanization. Circulation. 2001; 104:2746-53. | PubMed

3. Reddy KS and Yusuf S. Emerging epidemic of cardiovascular disease in developing countries. Circulation. 1998; 97:596-601. I PubMed

4. Joshi P, Islam S, Pais P, Reddy S, Dorairaj P, Kazmi K, Pandey MR, Haque S, Mendis S, Rangarajan S and Yusuf S. Risk factors for early myocardial infarction in South Asians compared with individuals in other countries. JAMA. 2007; 297:286-94. | Article | PubMed

5. Tragardh E, Claesson M, Wagner GS, Zhou S and Pahlm O. Detection of acute myocardial infarction using the 12-lead ECG plus inverted leads versus the 16-lead ECG (with additional posterior and right-sided chest electrodes). Clin Physiol Funct Imaging. 2007; 27:368-74. | Article | PubMed

6. Lau J, loannidis JP, Balk EM, Milch C, Terrin N, Chew PW and Salem D. Diagnosing acute cardiac ischemia in the emergency department: a systematic review of the accuracy and clinical effect of current technologies. Ann Emerg Med. 2001; 37:453-60. | Article I PubMed

7. Antman EM, Anbe DT, Armstrong PW, Bates ER, Green LA, Hand M, Hochman JS, Krumholz HM, Kushner FG, Lamas GA, Mullany CJ, Ornato JP, Pearle DL, Sloan MA, Smith SC, Jr., Alpert JS, Anderson JL, Faxon DP, Fuster V, Gibbons RJ, Gregoratos G, Halperin JL, Hiratzka LF, Hunt SA and Jacobs AK. ACC/AHA guidelines for the management of patients with ST-elevation myocardial infarction; A report of the American College of Cardiology/American Heart Association Task Force on Practice Guidelines (Committee to Revise the 1999 Guidelines for the Management of patients with acute myocardial infarction). J Am Coll Cardiol. 2004; 44:E1-E211. | Article | PubMed

8. Chu SG, Becker RC, Berger PB, Bhatt DL, Eikelboom JW, Konkle B, Mohler $E R$, Reilly MP and Berger JS. Mean platelet volume as a predictor of cardiovascular risk: a systematic review and meta-analysis. J Thromb Haemost. 2010; 8:148-56. | Article | PubMed Abstract | PubMed FullText

9. Bath PM and Butterworth RJ. Platelet size: measurement, physiology and vascular disease. Blood Coagul Fibrinolysis. 1996; 7:157-61. | PubMed

10. Hutt R, Ogunniyi SO, Sullivan MH and Elder MG. Increased platelet volume and aggregation precede the onset of preeclampsia. Obstet Gynecol. 1994; 83:146-9. I PubMed

11. Bilgic IC, Gelecek S, Ozmen MM and Kasapoglu B. The association of elevated mean platelet volume with the outcome of acute mesenteric ischemia. Blood Coagul Fibrinolysis. 2015; 26:727-30. | Article | PubMed

12. Khode V, Sindhur J, Kanbur D, Ruikar K and Nallulwar S. Mean platelet volume and other platelet volume indices in patients with stable coronary artery disease and acute myocardial infarction: A case control study. J Cardiovasc Dis Res. 2012; 3:272-5. | Article | PubMed Abstract | PubMed FullText

13. Damodar S, Ganesh KV and Murthy S. Mean platelet volume does not predict risk of myocardial infarction or coronary artery disease in Indian patients. Platelets. 2008; 19:80-1. | Article | PubMed

14. Alpert JS, Thygesen K, Antman E and Bassand JP. Myocardial infarction redefined--a consensus document of The Joint European Society of Cardiology/American College of Cardiology Committee for the redefinition of myocardial infarction. J Am Coll Cardiol. 2000; 36:959-69. | Article | PubMed

15. Thompson CB, Diaz DD, Quinn PG, Lapins M, Kurtz SR and Valeri CR. The role of anticoagulation in the measurement of platelet volumes. Am J Clin Pathol. 1983; 80:327-32. I PubMed

16. Dastjerdi MS, Emami T, Najafian A and Amini M. Mean platelet volume measurement, EDTA or citrate? Hematology. 2006; 11:317-9. | Article PubMed

17. Yekeler S, Akay K and Borlu F. Comparison of MPV and PLT Values in Patients with and without Diagnosis of Acute Coronary Syndrome. Journal of the American College of Cardiology. 2013; 62:116-116.

18. Jorgensen KA and Dyerberg J. Platelets and atherosclerosis. A review on the role of platelets in atherosclerosis with special reference to the role of polyunsaturated 20 carbon fatty acids. Dan Med Bull. 1980; 27:253-9. I PubMed

19. Prats E, Civeira E, Abos MD, Garcia-Lopez F and Banzo J. Tc-99m HMPAO labeled platelets in the detection of left ventricular thrombosis post acute myocardial infarction. Clin Nucl Med. 1996; 21:864-6. I Article | PubMed

20. Kutlucan A, Bulur S, Kr S, Onder E, Aslantas Y, Ekinozu I, Aydn Y and Ozhan $H$. The relationship between mean platelet volume with metabolic syndrome in obese individuals. Blood Coagul Fibrinolysis. 2012; 23:38890. | Article | PubMed

21. Bulur S, Onder HI, Aslantas Y, Ekinozu I, Kilic AC, Yalcin S and Ozhan H. Relation between indices of end-organ damage and mean platelet 
Agrawal et al. Cardiovascular System 2015,

volume in hypertensive patients. Blood Coagul Fibrinolysis. 2012; 23:367-9. | Article | PubMed

22. Lippi G, Meschi T and Borghi L. Mean platelet volume increases with aging in a large population study. Thromb Res. 2012; 129:e159-60. | Article | PubMed

23. Pathansali R, Smith $N$ and Bath P. Altered megakaryocyte-platelet haemostatic axis in hypercholesterolaemia. Platelets. 2001; 12:292-7. I Article | PubMed

24. Martin JF, Bath PM and Burr ML. Influence of platelet size on outcome after myocardial infarction. Lancet. 1991; 338:1409-11. | Article | PubMed

25. Sharpe PC and Trinick T. Mean platelet volume in diabetes mellitus. $Q \mathrm{~J}$ Med. 1993; 86:739-42. | PubMed

26. Hendra TJ, Oswald GA and Yudkin JS. Increased mean platelet volume after acute myocardial infarction relates to diabetes and to cardiac failure. Diabetes Res Clin Pract. 1988; 5:63-9. | Article | PubMed

27. Ayhan Tuzcu E, Arica S, Ilhan N, Daglioglu M, Coskun M, Ilhan O and Ustun I. Relationship between mean platelet volume and retinopathy in patients with type 2 diabetes mellitus. Graefes Arch Clin Exp Ophthalmol. 2014; 252:237-40. | Article | PubMed

28. Schneider DJ. Factors contributing to increased platelet reactivity in people with diabetes. Diabetes Care. 2009; 32:525-7. | Article | PubMed Abstract | PubMed FullText

29. Tschoepe D, Roesen P, Kaufmann L, Schauseil S, Kehrel B, Ostermann $H$ and Gries FA. Evidence for abnormal platelet glycoprotein expression in diabetes mellitus. Eur J Clin Invest. 1990; 20:166-70. | PubMed

30. Martin JF, Plumb J, Kilbey RS and Kishk YT. Changes in volume and density of platelets in myocardial infarction. Br Med J (Clin Res Ed). 1983; 287:456-9. | PubMed Abstract | PubMed FullText

31. Huczek Z, Kochman J, Filipiak KJ, Horszczaruk GJ, Grabowski M, Piatkowski R, Wilczynska J, Zielinski A, Meier B and Opolski G. Mean platelet volume on admission predicts impaired reperfusion and longterm mortality in acute myocardial infarction treated with primary percutaneous coronary intervention. J Am Coll Cardiol. 2005; 46:284-90. | Article | PubMed

32. Martin J, Bath PMW and Burr ML. Increased platelet size following myocardial infarction is associated with subsequent death and nonfatal reinfarction. Lancet. 1991; 338:1409-1411.

33. Pereg D, Berlin T and Mosseri M. Mean platelet volume on admission correlates with impaired response to thrombolysis in patients with ST-elevation myocardial infarction. Platelets. 2010; 21:117-21. | Article I PubMed

34. Slavka G, Perkmann T, Haslacher H, Greisenegger S, Marsik C, Wagner $\mathrm{OF}$ and Endler $\mathrm{G}$. Mean platelet volume may represent a predictive parameter for overall vascular mortality and ischemic heart disease. Arterioscler Thromb Vasc Biol. 2011; 31:1215-8. | Article | PubMed

\section{Citation:}

Agrawal BK, Manchanda B, Garg A, Mittal A, Mahajan $\mathrm{NC}$ and Agrawal U. Mean platelet volume in acute myocardial infarction: a case-controlled study. Cardio Vasc Syst. 2015; 3:6.

http://dx.doi.org/10.7243/2052-4358-3-6 